\title{
Evaluation and Optimization of Cooling System for Generator and Bearing at Cirata Hydroelectric Power Plant
}

\author{
Hariyanto $^{1}$, Ary Bachtiar ${ }^{2}$
}

\begin{abstract}
Cirata hydroelectric is located in Purwakarta district, West Java, Indonesia. The cooling system is one of the main equipment in the hydroelectric generator that serves to cool the generator and bearing. In recent years, water quality has been a decreased in Cirata dam causing high levels of corrosion rate and abrasion of piping and heat exchanger equipment. Currently, the modification of the cooling system from open loop into closed loop at unit 1 has occurred. This study aims to optimize the closed loop cooling system in order to be able to serve all heat exchangers with better heat effectiveness and low cost. Second, it aims to evaluate the closed loop cooling system before and after optimization. The optimization analysis of the closed loop system was conducted by means of redesigning the shell and tube heat exchangers by referring to TEMA standards through tube diameter variations (1/2", 5/8" and $3 / 4 ")$. These diameter variations aim to know the effect on heat transfer performance, such as the number of tubes, overall thermal transfer coefficient, total heat transfer surface area, and heat exchange cost. After obtaining the most economical design of $\mathrm{HE}$ (heat exchanger), the CBA evaluation of the closed loop cooling system was carried out through the NPV method. The results show that the larger used tube diameter decreases the number of tubes, while the heat transfer surface area increases as a result of the decrease in the overall heat transfer coefficient. The decreased number of tubes from 1/2" to $5 / 8$ " tube diameter is by $17.9 \%$ and the increased heat exchange production cost is by $2.18 \%$. In case of the tube diameter increase from $5 / 8$ " to $3 / 4$ ", a decrease in the number of tubes occurs by $7.9 \%$ and an increase in the heat exchange rate occurs by $4.07 \%$. The total cost of the existing closed loop cooling system compared to the redesigned one decreases by $7.7 \%$.
\end{abstract}

Keywords-Shell and Tube, TEMA, Tube Diameter, Effectiveness, CBA.

\section{INTRODUCTION}

Cirata consists of 8 hydroelectric units that have a total capacity of $1008 \mathrm{MW}$ and the capacity of each unit is 126 MW. Cirata Hydroelectric Power Plant uses Cirata reservoir water as the cooling medium.

As time goes by, the water quality in the reservoir dam has decreased, resulting in high rates of corrosion and abrasion in piping and heat exchanger equipment. Now the cooling system has been modified from open loop into

${ }^{1}$ Hariyanto is with Java-Bali Power Generating Company (PT. PJB), West-Java, Indonesia. E-mail: hariyanto@ptpjb.com.

${ }^{2}$ Ary Bachtiar is with Department of Mechanical Engineering, Institut Teknologi Sepuluh Nopember (ITS), Surabaya, 60111, Indonesia. E-mail: ary bachtiar@me.its.ac.id. closed loop at unit 1 . This study aims to optimize the closed loop cooling system so that it can be used to serve all heat exchangers with better heat effectiveness and lower cost. Conducts research to get optimum design parameters obtained from oil cooler shell and tube heat recovery exchangers at Sarcheshmeh copper production plant located in the south of Kerman, Iran[1]. The author proves that the optimization design method based on the constructal theory for shell and tube heat exchangers with two parts series can increase the effectiveness more than $28 \%$ compared to normal shell and tube heat exchangers under the same condition. Therefore, it is important to propose a study on the optimization of closed loop cooling system at Cirata HEPP.

The optimization of closed loop system was conducted by means of redesigning the shell and tube heat exchangers by referring to TEMA standards through tube diameter variations (1/2", 5/8" and 3/4"). In the presented optimization problem, the optimal values of tube diameter and tube number were found by the trade-off between maximizing the effectiveness and minimizing the total cost.

\section{METHOD}

Over the past few years, optimization of heat exchanger design has been analyzed from different points of view and with using different optimization techniques. Proposes a method that is motivated by the constructal theory[2]. In this method, a global heat exchanger is divided into several sub-heat exchangers into series and parallel arrangements. A genetic algorithm, followed by the Tubular Exchanger Manufacturers Association (TEMA) standards, is applied to minimize the objective function, which is set at the total cost of the shell and tube heat exchangers. The results of three case studies demonstrate that the new design approach can significantly reduce the total cost compared to the methods of original design; traditional genetic algorithm design and old constructal design. Proposes a novel heat exchanger, a so-called constructal shell and tube heat exchangers, to maximize the access of the cold stream to the heat flux of the hot stream and minimize the thermal resistance[3]. Azad and co-workers use a genetic algorithm, based on the constructal theory, to optimize the objective function, which is a mathematical model for the total cost of the shell and tube heat exchangers. According to their design method, constructal heat exchangers with more than two sections in series have higher costs compared to the 
heat exchangers with two sections. The results demonstrate a significant reduction in total cost (more than 50\%) compared to the original design. Conducts thermal modeling of industrial shell and tube heat exchangers (using e-NTU method and Belle Delaware approach for estimating the shell-side heat transfer coefficient and pressure drop)[4]. Shell and tube heat exchangers were optimally designed by defining two objective functions (total cost and effectiveness) and applying the genetic algorithm technique. The effectiveness is maximized and the total cost is minimized. The design parameters (decision variables) are tube arrangement, baffle cut ratio, tube pitch ratio, tube length, tube number, baffle spacing ratio and 20 standard tube diameters. A set of Pareto optimal points is obtained and shown. The results clearly reveal the level of conflict between two objective functions. Tube pitch ratio, tube length, tube number and baffle spacing ratio are found to be important design parameters causing a conflict between the effectiveness and total cost. On the other hand, no or weak effect on the conflict between two optimized objective functions is observed for design parameters such as tube arrangement.

\section{A. Thermal Modeling}

Data for modeling input is taken from design data, commissioning data, operating data that is[5] .

1) The Heat load of the heat exchanger presented in[6] as follows:

$\mathrm{q}=\mathrm{m}_{\mathrm{c}} \mathrm{c}_{\mathrm{p}}\left(\mathrm{T}_{\mathrm{co}}-\mathrm{T}_{\mathrm{ci}}\right)=\mathrm{m}_{\mathrm{h}} \mathrm{c}_{\mathrm{p}}\left(\mathrm{T}_{\mathrm{hi}}-\mathrm{T}_{\mathrm{ho}}\right)$

The Heat transfer area and number of tubes are calculated by Eqs (2) and (3)

$$
\mathrm{A}=\frac{q}{U \cdot F \cdot \Delta T_{l m t d}}
$$

A $\quad=n \cdot \pi d L$

The LMTD and correction factor are calculated by Eqs (4) and (5)

$$
\Delta \mathrm{T}_{\mathrm{LMTD}}=\frac{\left(T_{h o}-T_{c i}\right)-\left(T_{h i}-T_{c o}\right)}{\ln \left(\frac{T_{h o}-T_{c i}}{T_{h i}-T_{c o}}\right)} K
$$

correction factor $\mathrm{F} \quad \mathrm{P}=\frac{t_{c o}-t_{c i}}{T_{h i}-t_{c i}} ; \mathrm{R}=\frac{T_{h i}-T_{h o}}{t_{c o}-t_{c i}}$

2) The overall heat transfer coefficient " $U$ " is calculated with the following formula:

$$
U=\frac{1}{\frac{1}{h_{i}}+R \text { ftube }+\frac{\ln \left(r_{O} / r_{i}\right)}{2 \pi k L}+R_{f s h e l l}+\frac{1}{h_{O}}}
$$

3) The convection heat transfer coefficient in the tube side presented in [6] as follows:

$$
\mathrm{h}_{\mathrm{o}}=N u \frac{k}{d_{i}}
$$

The Reynolds number and Nusselt number are calculated by Eqs (4) and (5)

$$
\begin{aligned}
& \mathrm{R}_{\mathrm{ed}}=\frac{V \cdot d_{i} \cdot \rho}{\mu} \\
& \mathrm{Nu}_{\mathrm{d}}=0,023 \mathrm{Re}^{0,8} \mathrm{Pr}^{\mathrm{n}}
\end{aligned}
$$

4) The convection heat transfer coefficient in the shell side is presented in[7] as follows:

$$
\mathrm{h}_{\mathrm{o}} \quad \mathrm{Nu} \frac{k}{D_{e}}
$$

The Reynolds number and Nusselt number are calculated by Eqs (11) and (12)

$$
\begin{aligned}
& \mathrm{R}_{\mathrm{ed}}=\frac{D_{e} \cdot G_{s}}{\mu_{h}} \\
& \left.\mathrm{Nu}_{\mathrm{d}}\right)=0,36 \operatorname{Re}^{0,55} \operatorname{Pr}^{0.33}\left(\mu_{b} / \mu_{w}\right)^{0.14}
\end{aligned}
$$

The hydraulic diameter, Mass velocity and Cross flow area are calculated by Eqs (13), (14) and (15)

$$
\begin{aligned}
\mathrm{D}_{\mathrm{e}}= & \frac{4\left(0,5 P_{T} 0,86 P_{T}-\left(\left(0,5 \cdot \pi \cdot d_{o}{ }^{2}\right) / 4\right)\right)}{0,5 \cdot \pi \cdot d_{o}} \\
\mathrm{a}_{\mathrm{s}} & =\frac{C \cdot B \cdot D_{s}}{P_{T}} \\
\mathrm{G}_{\mathrm{s}} & =\frac{m_{h}}{\boldsymbol{a}_{\mathrm{s}}}
\end{aligned}
$$

5) The heat capacity ratio (Cr), and the number of transfer units (NTU), are presented in[6] as follows:

$$
\begin{aligned}
& C r=C \min / \text { Cmax }: C h=\dot{m h} C p, ; C c=\dot{m} c C p \\
& \mathrm{NTU}=\frac{U \cdot A}{C_{\min }}
\end{aligned}
$$

The Effectiveness, $q_{\max }$ and $q_{a c t}$ are calculated by Eqs (18), (19) and (20)

$$
\begin{aligned}
& \text { Effectiveness } \mathcal{E}=q_{a c t} / q_{\max } ; \varepsilon=f\left(\mathrm{NTU}, \frac{C_{\min }}{C_{\max }}\right) \\
& \mathrm{q}_{\max }=C_{\min }\left(T_{h i}-T_{c i}\right) \\
& \mathrm{q}_{\text {act }}=C_{h}\left(T_{h i}-T_{h o}\right)
\end{aligned}
$$

6) The shell diameter is presented in[7] as follows:

$$
\begin{aligned}
& \mathrm{D}_{\mathrm{s}}=\sqrt{\frac{N t .4 A 1}{C T P . . \Pi}} \\
& \mathrm{A} 1=\mathrm{CL} . \mathrm{P}_{\mathrm{t}}{ }^{2}
\end{aligned}
$$


7) The total pressure drop of the tube side and shell side are presented in [6] as follows:

$$
\Delta \mathrm{P}_{\text {tube }}=4 f \frac{L \cdot N_{p}}{d_{i}} \rho \frac{u_{m}{ }^{2}}{2}+4 N_{p} \frac{\rho \cdot u_{m}{ }^{2}}{2}
$$

\section{B. Optimization Procedure}

1) Cost benefit analysis is presented in [8] as follows:

In this study, the operating conditions of the equipment life period is ny $=20 \mathrm{yr}$. The total cost of the objective function is assumed to be like:

$$
\begin{aligned}
& \text { Ctot }=\mathrm{Ci}+\mathrm{Co} \\
& \mathrm{PV} \text { Cost }=\frac{C_{1}}{(1+i)^{n 1}}+\frac{C_{2}}{(1+i)^{n 2}}+\ldots \frac{C_{n}}{(1+i)^{n}}
\end{aligned}
$$

\section{RESULTS AND DISCUSSION}

The objectives of this study are to increase duty, effectiveness while minimizing the total cost. The mass flow rate of hot water is $141.1 \mathrm{~kg} / \mathrm{s}$ with $38.89{ }^{\circ} \mathrm{C}$ inlet temperature, entering the shell side. The mass flow rate of cold water is $181.6 \mathrm{~kg} / \mathrm{s}$ with $27.4{ }^{\circ} \mathrm{C}$ inlet temperature, entering the tube side. The total duty is $2822.68 \mathrm{~kW}$; tube length is $2.438 \mathrm{~m}$; and shell diameter is $1.15 \mathrm{~m}$ in maximum. In this study, the equipment life period is 20 years; the rate of annual discount is $12.05 \%$; the price of electricity is 0.06 $\$ / \mathrm{kWh}$; and the hour of operation is $2190 \mathrm{~h} / \mathrm{yr}$.

From fig. 3, The results of the obtained thermal modeling show that the larger the tube diameter is, the smaller the heat transfer coefficient value of the heat exchanger will be, resulting in the increased heat transfer surface area of the design of heat exchangers for the same amount of duty. The decrease in the heat transfer coefficient as a result of the increase in the used tube diameter of from $1 / 2$ " to $5 / 8$ " is by $5.3 \%$ and the one from $5 / 8$ " to $3 / 4$ " is by $10.6 \%$. While the increase in the heat transfer surface area of the tube diameter from $1 / 2$ " to $5 / 8$ " is by $6.1 \%$ and the one from $5 / 8$ " to $3 / 4$ " is by $11.23 \%$.

From table 1, the increase in the used tube diameter causes an increase in the production cost of heat exchangers. This condition is caused by an increase in the heat transfer surface area, thus increasing the need for the material cost of the heat exchangers. The large increase in the cost of using tube diameters from $1 / 2$ " to $5 / 8$ " is by $2.18 \%$ and the one from $1 / 2$ " to $3 / 4$ " is by $4.07 \%$. From the results of thermal modeling, it is found that two heat exchangers meet the criteria of total duty and the location dimensions for the placement of heat exchangers are in the tube diameter of $1 / 2$ " and 5/8”. By considering the condition of water quality and cleaning time, the heat exchanger with a diameter of $5 / 8$ " is chosen as an alternative solution since it has a smaller number of tubes so that the cleaning process is faster than the $1 / 2$ " diameter

Redesign results to gain larger capacity and effectiveness of heat exchangers on the same tube diameter usage cause an increased heat transfer surface area and the number of tubes. Table 2 shows that the temperatures of the heat exchangers do not increase significantly although the total cooling loads of the heat exchangers increase. This condition is due to the optimized flow rate of the cooling fluid following the current installed pump capacity. The design magnitude of the effectiveness of the current installed heat exchanger is $0.31 \%$ while the one of the effectiveness of the optimized heat exchanger is $0.42 \%$. This shows that the redesigned heat exchanger has better performance compared to the existing heat exchanger

\section{CONCLUSIONS}

From table 3, The design results of the heat exchanger show the same gain of heat exchanger effectiveness, that the larger the used tube diameter is, the greater the production cost of the heat exchanger will be. The magnitude of the increase in the cost of using the tube diameter from $1 / 2$ " to $5 / 8$ " is by $2.18 \%$ and the one from $1 / 2$ " to $3 / 4$ " is by $4.07 \%$. With the increase of the intermediate heat exchanger capacity, the closed loop cooling system is able to be used to serve the bearing side of the heat exchanger so that the heat exchanger life on the bearing side increases and the heat exchanger replacement cost drops. The analysis results of the total costs incurred in the optimization of the closed loop cooling system during the expected operating life of the equipment (20 years) decrease by the total cost of $7.7 \%$ compared with the existing closed loop cooling system.

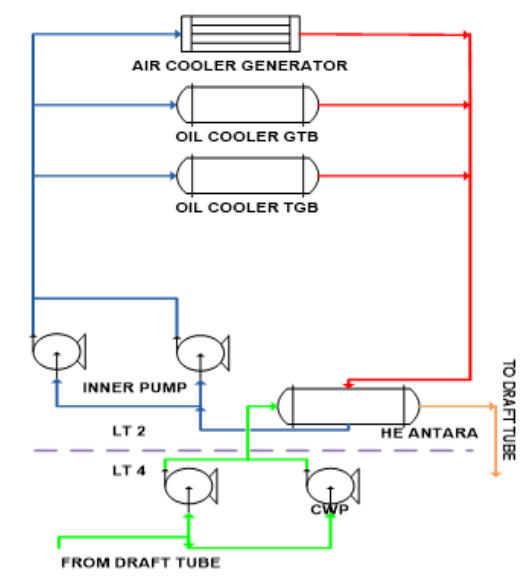

Figure 1. Close loop cooling system. 


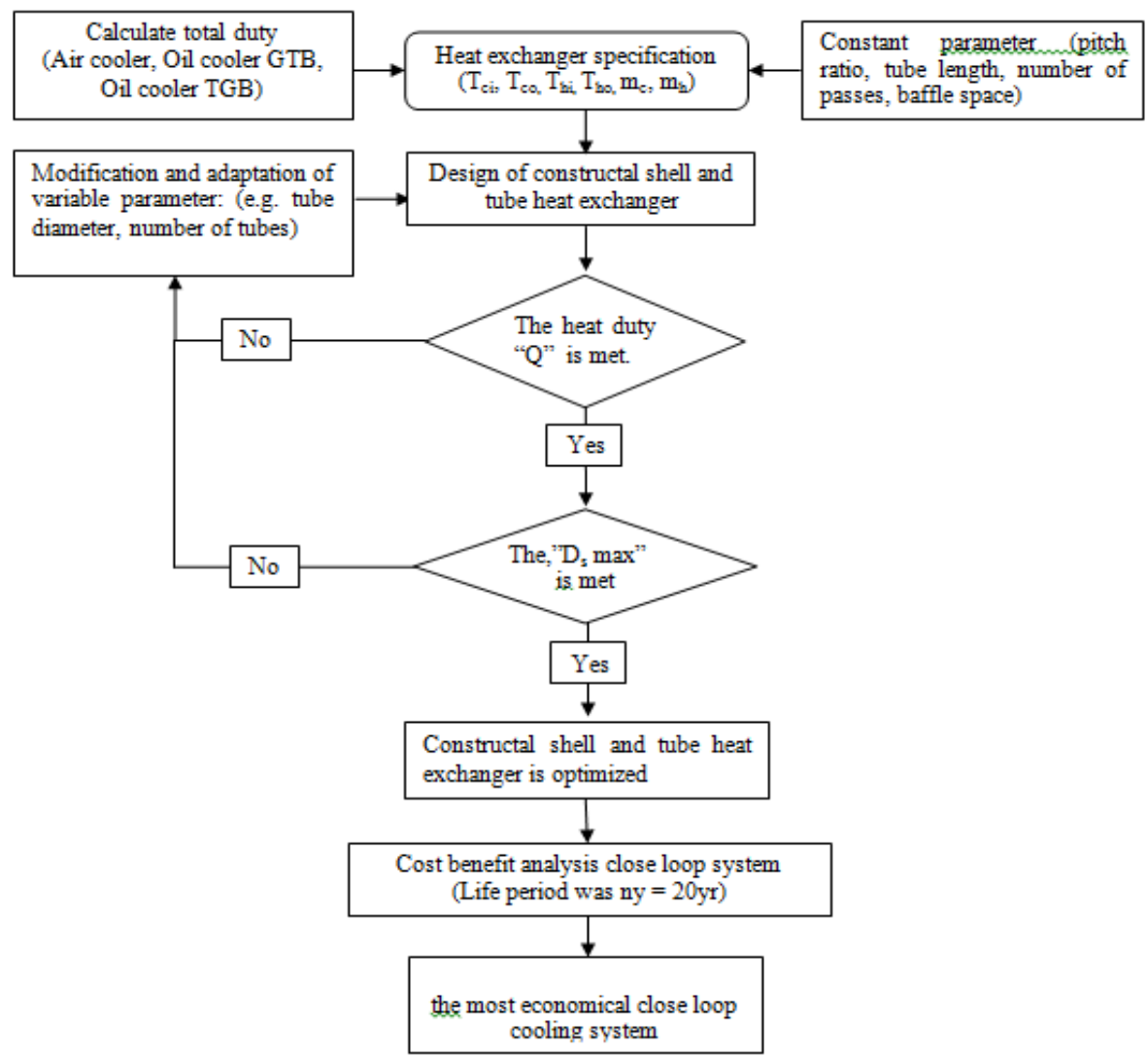

Figure 2. Flow chart of optimization procedure for closed loop cooling systems
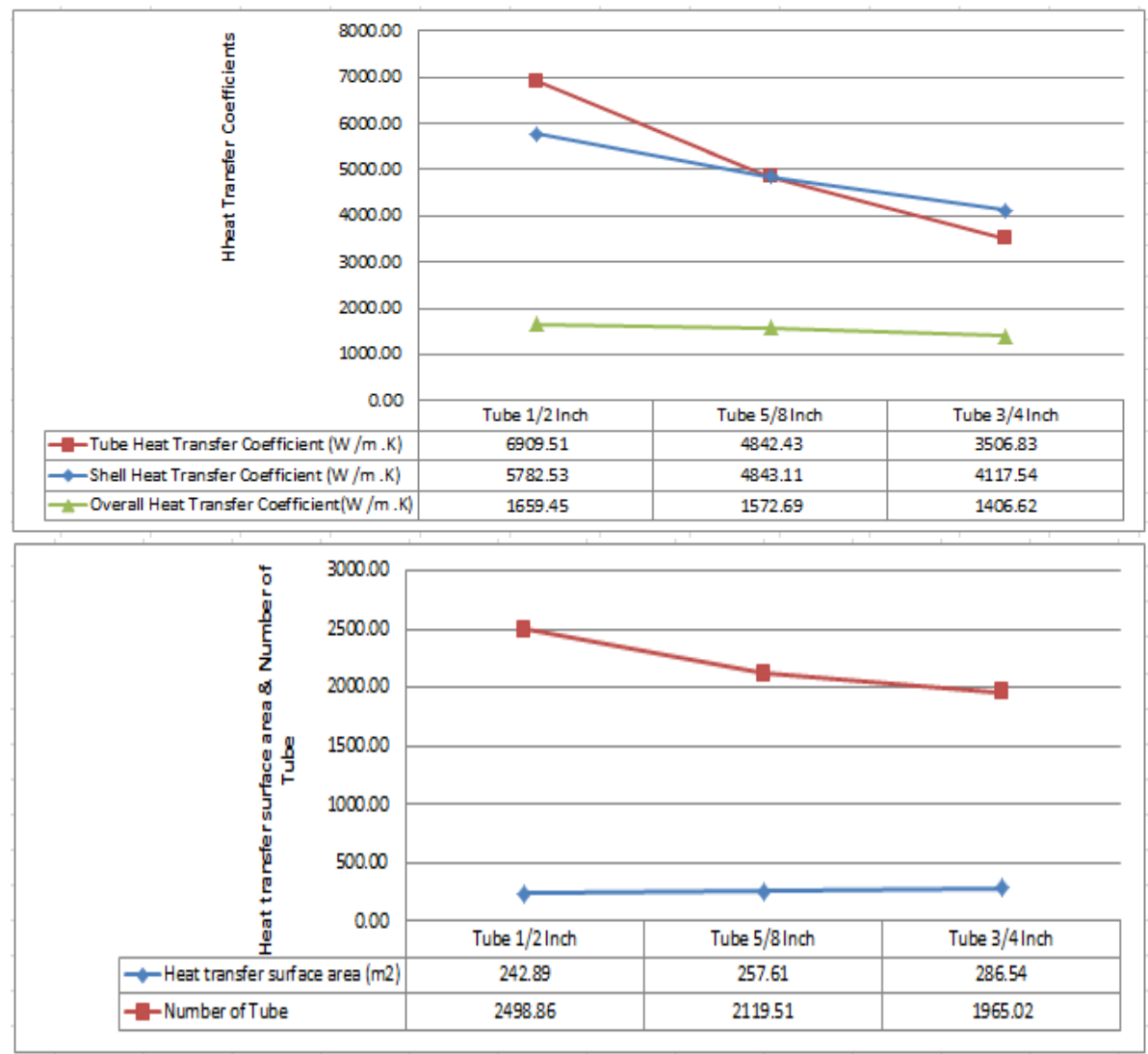

Figure 3. Comparison of heat transfer performance on shell and tube heat exchangers for (a) overall thermal transfer coefficient (b) heat transfer area and the number of tubes. 
TABLE 1.

COST COMPARISON OF THE HEAT EXCHANGERS WITH VARIATIONS IN TUBE DIAMETER

\begin{tabular}{ccc}
\hline \hline Nomenclature & Cost & Percentage (\%) \\
\hline HE Closed Loop Redesign (1/2") & Rp. 1,228,825,819,- & 100 \\
HE Closed Loop Redesign (5/8") & Rp. 1,255,599,241 & 102.18 \\
HE Closed Loop Redesign (3/4") & Rp. 1,278,877,599 & 104.07 \\
\hline \hline
\end{tabular}

TABLE 2.

COMPARISON BETWEEN MODELING RESULT AND DESIGN DATA ON SHELL AND TUBE HEAT EXCHANGERS

\begin{tabular}{|c|c|c|c|c|c|c|c|}
\hline \multirow{2}{*}{ Variables } & \multicolumn{3}{|c|}{ Existing Design } & \multicolumn{4}{|c|}{ New Design } \\
\hline & Hot Stream & \multicolumn{2}{|c|}{ Cold Stream } & \multicolumn{2}{|c|}{ Hot Stream } & \multicolumn{2}{|c|}{ Cold Stream } \\
\hline Mass flow rate, $\mathrm{m}_{\mathrm{o}}(\mathrm{kg} / \mathrm{h})$ & 416242 & \multicolumn{2}{|c|}{372195} & \multicolumn{2}{|c|}{508207} & \multicolumn{2}{|c|}{653719} \\
\hline Temperature, $\mathrm{T}\left({ }^{\circ} \mathrm{C}\right)$ & 38.7 & 29 & 32 & 38.89 & 34.1 & 27.4 & 31.12 \\
\hline Duty, Q (kW) & \multicolumn{3}{|c|}{1296.3} & \multicolumn{4}{|c|}{2822.68} \\
\hline LMTD (K) & \multicolumn{3}{|c|}{6.84} & \multicolumn{4}{|c|}{7.22} \\
\hline $\mathrm{Q} / \Delta \mathrm{T}(\mathrm{W} / \mathrm{K})$ & \multicolumn{3}{|c|}{189.523} & \multicolumn{4}{|c|}{390.953} \\
\hline Heat transfer surface area, $\mathrm{A}\left(\mathrm{m}^{2}\right)$ & \multicolumn{3}{|c|}{230.38} & \multicolumn{4}{|c|}{257.61} \\
\hline Pipe material & \multicolumn{3}{|c|}{ Cu-Ni 10 (ASTM C70600) } & \multicolumn{4}{|c|}{ Cu-Ni 10 (ASTM C70600) } \\
\hline Inner tube diameter, Do (mm) & \multicolumn{3}{|c|}{0.015875} & \multicolumn{4}{|c|}{0.015875} \\
\hline Outer tube diameter, Di (mm) & \multicolumn{3}{|c|}{0.013858} & \multicolumn{4}{|c|}{0.013858} \\
\hline Tube length, L (m) & \multicolumn{3}{|c|}{2.438} & \multicolumn{4}{|c|}{2.438} \\
\hline Fluid velocity, V (m/s) & \multicolumn{3}{|c|}{0.779} & \multicolumn{4}{|c|}{1.222} \\
\hline Tube pitch, $\mathrm{P}_{\mathrm{T}}(\mathrm{mm})$ & \multicolumn{3}{|c|}{0.022875} & \multicolumn{4}{|c|}{0.022543} \\
\hline Number of tubes & \multicolumn{3}{|c|}{1968} & \multicolumn{4}{|c|}{2120} \\
\hline Inner shell diameter, Ds (m) & \multicolumn{3}{|c|}{1.150} & \multicolumn{4}{|c|}{1.150} \\
\hline Baffle spacing, B (m) & \multicolumn{3}{|c|}{0.48} & & & & \\
\hline Number of baffles & & & & & & & \\
\hline Overall heat transfer coefficient, $\mathrm{U}\left(\mathrm{W} / \mathrm{m}^{2} . \mathrm{K}\right)$ & & .52 & & & & & \\
\hline
\end{tabular}

TABLE 3.

COMPARISON OF TOTAL COST EXISTING CLOSED LOOP COOLING SYSTEMS WITH A NEW DESIGN

\begin{tabular}{lcc}
\hline \multicolumn{1}{c}{ Cooling System } & Total Cost & Percentage (\%) \\
\hline HE Close Loop Redesign (5/8") & Rp. 9,982,755,790 & 100 \\
HE Close Loop Existing (5/8") & Rp. 10,751,461,691 & 107.70 \\
\hline \hline
\end{tabular}

\section{ACKNOWLEDGMENTS}

The work for this paper is performed within a program courtesy to PT Pembangkitan Jawa Bali

\section{REFERENCES}

[1] M. Mirzaei, H. Hajabdollahi, and H. Fadakar, "Multi-objective optimization of shell-and-tube heat exchanger by constructal theory,” Appl. Therm. Eng., vol. 125, pp. 9-19, Oct. 2017.

[2] J. Yang, A. Fan, W. Liu, and A. M. Jacobi, "Optimization of shelland-tube heat exchangers conforming to TEMA standards with designs motivated by constructal theory,” Energy Convers. Manag., vol. 78, pp. 468-476, Feb. 2014.

[3] A. V. Azad and M. Amidpour, "Economic optimization of shell and tube heat exchanger based on constructal theory," Energy, vol. 36, no. 2, pp. 1087-1096, Feb. 2011.
[4] S. Sanaye and H. Hajabdollahi, "Multi-objective optimization of shell and tube heat exchangers," Appl. Therm. Eng., vol. 30, no. 14-15, pp. 1937-1945, Oct. 2010.

[5] PT.PJB, Desain Modifikasi Sistem Pendingin Close Loop di UP Cirata. 2006.

[6] T. L. Bergman and F. P. Incropera, Fundamentals of heat and mass transfer., 7 ed. New Jersey: Wiley, 2011.

[7] S. Kakaç, H. Liu, and A. Pramuanjaroenkij, Heat exchangers: selection, rating, and thermal design, 3. ed. Boca Raton: CRC Press, 2012.

[8] P. W. O’Callaghan, Energy management. London: McGraw-Hill Book Co, 1993. 